\title{
ESTILO DE VIDA EN EL EJERCITO DE CHILE DURANTE EL SIGLO XVII
}

\author{
POR \\ JUAN EDUARDO VARGAS CARIOLA \\ Universidad de Chile \\ Universidad Católica de Chile
}

\section{INTRODUCCIÓN}

Los estudios más recientes sobre el mundo militar durante el siglo XVII —como los de Geoffrey Parker (1) y André Corvisier (2) por ejemplo- se han orientado a dilucidar, entre otros, temas tales como la movilización, el problema del mantenimiento, los recursos financieros y el estilo de vida en los ejércitos de dicha época. En cuanto a este último las investigaciones citadas ofrecen interesantes aproximaciones y sugerentes planteamientos sobre aspectos tales como la vivienda de los soldados, su vestido, alimentación, enfermedades, delitos, camaradería y religiosidad.

En el caso de Chile, es poco lo que se sabe sobre el estilo de vida en el ejército de la Frontera. Mas aún, diríamos que es un tema no abordado por la investigación, lo que posiblemente se deba a que no se cuenta con las fuentes más fundamentales que podrían haber proporcionado datos sobre el particular. En este sentido, hay que mencionar que las hojas de vida, en las que se anotaban la edad de los soldados, sus señas físicas, origen, faltas a la disciplina, delitos y carrera militar, no se encuentran en nuestros archivos ni en los archivos españoles. Que tampoco hay

SigLA UTILIZADA:

AGI: Archivo General de Indias, Sevilla.

(1) Geoffrey Parker, El ejército de Flandes y el camino español 1657-1659. Madrid. Biblioteca de la Revista de Occidente, 1976.

(2) André Corvissier, Les control de troupes de l'Ancien Régime. 2 vols. Paris. Ministere des Armees. Service Historique, 1968. También Armées el societes en Europe de 1494 a 1789. Presses Universitares de France. Vendome, 1976; y Sources et methodes de l'histoire social et psicologique de l'armée françois aut $X V I I$ siècle. $\mathrm{S} / \mathrm{p}$ de $\mathrm{i}$. 
rastros de la documentación del hospital de Concepción que, entre otras cosas, podría haber of recido noticias sobre las causas más frecuentes de enfermedades y muertes de los militares. Y que lo mismo ocurre con los testamentos de estos últimos que, con todas las limitaciones que se quieran, deberian haber proporcionado luces sobre sus edades, orígenes, matrimonios y bienes.

Sin esas fuentes, el investigador que intenta reconstruir el estilo de vida de los militares no tiene más remedio que aprovechar los datos que se encuentran en los cronistas, en los informes sobre el ejército que los gobernadores y la real audiencia dirigían regularmente al monarca, en los informes que prepararon los visitadores - después de concluir sus comisiones en Concepcióny, por último, en las causas que los tribunales militares seguían a los miembros del ejército. En todo caso, conviene precisar que las fuentes indicadas no proporcionan gran cantidad de material. Los cronistas, por ejemplo -en particular González de Nájera, Pineda y Bascuñán, el padre Rosales y Jerónimo de Quirogacentran sus narraciones en cuestiones muy distintas al estilo de vida en el ejército, no siendo abundantes - aunque sí valiosassus descripciones sobre este último. Los gobernadores y la real audiencia, por su parte, cuando se refieren a esa fuerza, se ocupan de otra clase de problemas, y sólo al pasar mencionan asuntos relacionados con dicho tema. Los informes de los visitadores, a su turno, que debieran ser una fuente de gran utilidad son poco aprovechables. Hay que apuntar al respecto que sólo se conocen antecedentes - bastante incompletos, por lo demás- de una de las cinco visitas que, a lo menos, se realizaron al ejército durante el siglo XVII. Por último agreguemos que prácticamente no se conserva la documentación de las causas militares incoadas durante dicha centuria, y que la única aprovechable corresponde al juicio que se inició en contra de los miembros del ejército que se amotinaron a comienzos del siglo XVIII (3).

Teniendo en cuenta las limitaciones indicadas, resulta necesario advertir que las afirmaciones y sugerencias que se formulan en este artículo deben considerarse tan sólo como una aproximación al estilo de vida de los militares en la Frontera, a la

(3) El juicio, que se inició en el mes de enero de 1703, puede utilizarse como fuente para los últimos años de la centuria anterior. En primer lugar, porque no hay mayores diferencias entre el ejército de fines del siglo XVII y de comienzos del XVIII, y, en segundo término porque la causa del motín -esto es el malestar de los soldados por no recibir sus pagos regularmente- se generó en la última década del siglo XVII. 
espera que nuevas investigaciones proporcionen otros antecedentes que posibiliten reconstruir una visión más definitiva sobre este tema.

\section{LA VIVIENDA}

A lo largo del siglo XVII, el número de soldados del ejército de Chile experimentó significativas variaciones. Así en 1605 , se contabilizaban 2.199 plazas, descendiendo a 1.200 en 1616. Desde entonces y hasta el alzamiento de 1655, su número fluctuó entre los 1.500 y los 1.700 hombres, para subir a poco más de los dos mil a comienzos de la década de 1660 . A partir de la siguiente, las plazas del ejército descenderán a lo que parecen sus niveles históricos, esto es, de 1.500 a 1.700 soldados, para bajar a tan sólo 960 hombres en los últimos años del siglo (4).

Las cantidades de soldados indicadas se distribuían entre los dos presidios, instalados en las ciudades de Concepción y Chillán, los dos tercios y los fuertes que en un número que varió a lo largo del siglo, había en la Frontera (5). En 1633, servían 172 hombres en los presidios, esto es, el 11,51\% del total de soldados que tenía el ejército entonces, 181 (el 12,11\%) se encontraban instalados en cinco fuertes (6) y los demás, que en total llegaba a 1.141 soldados (76,37 \%) servían en los dos tercios (7). Las cantidades apuntadas, como se dijo, variaron a lo largo del siglo. Así y todo, da la impresión que los porcentajes se mantuvieron en cifras parecidas, por lo que podría afirmarse que alrededor del $25 \%$ de los soldados se distribuyeron entre los presidios y fuertes, y que el resto lo hizo en los dos tercios que existían en la Frontera.

De la información reunida se infiere, en primer lugar, que dichos emplazamientos defensivos experimentaron ciertos cam-

(4) Juan Eduardo Vargas Cariola, El ejércilo de Chile en el siglo XVII. Sevilla. Tesis doctoral (inédita). Universidad de Sevilla, 1981, págs. 189 y ss.

(5) Sobre las ubicaciones y traza de esos emplazamientos defensivos puede verse la obra de Gabriel GuARDA, Flandes Indiano. Santiago. Ediciones Universidad Católica de Chile, 1990, p. 189 y ss.

(6) Los fuertes que hemos considerado para nuestro cálculo son Buena Esperanza, Nacimiento. San Juan de Talcamávida, San Pedro y San Miguel de Colcura. No incluimos los fuertes de Quinchamalí y Larequete, porque eran servidos por soldados que se enviaban, al primero desde el presidio de Chillán, y al último desde el tercio de Arauco. El fuerte de Labu quedó fuera de los cálculos por carecerse de información sobre la cantidad de soldados que servían en él.

(7) VARGAS, [4] págs. 
bios a lo largo del siglo XVII. El cronista Alonso González de Nájera, que conoció el mundo militar a comienzos de esa centuria narra que

son... los fuertes... en cuanto a su materia, algunos dos o tres tapias, como lo es el más principal, que es el de Arauco, pero todos los demás son de palizada, quiero decir, de unos palos los más derechos que se hallan a mano del sitio donde se fundan con la rustiquez que se cortan, y de grosor indiferente, que los más lo son, serán poco más que el timón o pértigo de un carro, y de altura de catorce o quince pies, cual más y cual menos, los cuales plantados hasta una rodilla o tres palmos, bien firmes, ajuntados unos con otros, van de tal manera haciendo hilera por lo diseñado componiendo y cerrando la circunferencia o espacio del trazado sitio. Los cuales palos vienen a ser las murallas de los fuertes, con otros más delgados atravesados, que van abrazando por la parte de dentro los plantados, a que llaman cintas, porque ciñen a los otros divididos en cuanto su altura en convenientes distancias, bien atados con ellos con látigos o correas de cuero crudio de vaca, que son las comunes sogas de aquella tierra. Tienen algunos destos fuertes por la parte de dentro otra palizada la mitad más baja que la de fuera, distante della cinco o seis pies, el cual hueco o vacío de entre la una y la otra se terraplena todo a la redonda de fagina y tierra, de manera que el tal terraplén viene a servir de muralla al fuerte, donde se pasean las rondas y se ponen los convenientes centinelas, y de donde, finalmente, se pelea y está a la defensa detrás de los débiles y flacos parapetos, que es lo que sobrepuja la primera y principal palizada de defuera, a cuya causa en los combates hieren y matan los enemigos muchos soldados con sus largas picas por entre los palos ... La forma figura o traza que tienen estos fuertes, es comúnmente cuadrada con algunos traveses y en su grandeza diferentes, respecto de la guarnición que los ha de sustentar y defender, y comarca do se fundan (8).

Alonso González de Nájera llegó a Chile en 1601 y regresó a España a mediados de 1607. Poco tiempo después, según el cronista Luis Tribaldos de Toledo, se habría comenzado a generalizar la "tapiería" en los fuertes y tercios; esto porque resultaba un elemento defensivo más eficaz frente a los ataques de los

(8) Alonso González de Nájera, Desengaño y reparo de la Guerra del Reino de Chile. Santiago, Ed. Andrés Bello Santiago, 1971, pág. 181 y 182 
indios y porque la madera, que hasta entonces se utilizaba para proteger los fuertes, no resistía el peso de la artillería que era menester instalar (9).

En su interior, los tercios y los fuertes presentaban una suerte de núcleo en el que se concentraban los edificios principales de los mismos. En el caso del tercio de Arauco, dicho lugar está compuesto por la plaza de armas, alrededor de la cual se distinguía la iglesia, la casa del cura, con sus oficinas, la casa de la "guardia", la del maestre de campo, "en clausura con corredores por de dentro y fuera", la del capitán de caballería, más sencilla que la anterior, y los almacenes donde se guardaban los alimentos, armas y ropa que se entregaba a los soldados. En torno a dicho centro, y parece que sin un orden determinado, se construían las "galeras" que servían de alojamiento a los militares (10). El núcleo del tercio de Yumbel, por su parte, no parece muy diferente al de Arauco (11). En los fuertes, aunque en forma más modesta, se repetía la misma estructura interna de los tercios; esto es, un centro en el que se levantaban los edificios principales y las "galeras" de los soldados a su alrededor.

Las primeras referencias sobre las "galeras" en las que vivían los soldados proceden de González de Nájera. «El alojamiento de la gente - anota al cronista - son barracas de carrizo, materia bien apta al fuego, por lo que están estos fuertes con sus murallas muy sujetos a incendios" (12). Tribaldos de Toledo, por su parte, sobre la base de un informe de la real audiencia de Santiago del año 1611 , indica que los fuertes tenían «unas ruines empalizadas, con otras más ruines varracas o chozuelas para la gente de guerra..." (13). De acuerdo con descripciones posteriores puede decirse que en los tercios y en algunos fuertes, hubo una cierta

(9) Luis Tribaldos DE Toledo, "Historia General de las continuadas guerras y dificil conquista del Gran Reino y provincias de Chile desde su primer descubrimiento por la nación española en el orbe antártico hasta la era presente" (1630), en Colección Muñoz, de la Real Academia de la Historia de Madrid, f. 48 vta y 49. También se refiere a esta évolución Pedro CunILl Grau, "Chile meridional criollo: su geografía humana en 1700" en Cuadernos Geográficos del Sur, $\mathrm{n}^{\boldsymbol{Q}} 1$ Concepción Instituto de Geografía. Universidad de Concepción, p. 47.

(10) Descripción del tercio de Arauco en 1690, en AGI, Chile, 129, del año 1709 en AGI, Chile, 130 y plano del mismo del año 1741, en AGI Mapas y planos de Perú y Chile, no 23. También describen dicho tercio Cunils, [ 9 ] págs. 47-49, y Gabril Guarda, "Influencia militar en las ciudades del Reino de Chile" en Boletin de la Academia Chilena de la Historia, Santiago, no 75, págs. 16-18 y del mismo autor Historia Urbana del Reino de Chile. Santiago, Ed. Andrés Bella, 1978, pág. 250-252.

(11) El tercio de Yumbel en 1709 en AGI, Chile 130.

(12) Gonzálezz. de Nájera [8], pág. 182.

(13) Tribaldos [9], fols. 111 y 111 vta. 
evolución de la vivienda. Así, sabemos por un informe del año 1709 que, en el tercio de Arauco, había "galeras" de adobe y teja para los soldados y los oficiales (14) y que en los fuertes Purén y San Diego de Tucapel dichas viviendas se construyeron de murallas de adobe y techos de paja. En los fuertes Santa Juana y Nacimiento, en cambio, las kgaleras" seguían siendo "casas de paja" (15), tal vez no muy diferentes a las que se levantaron como habitaciones en los fuertes y tercios a comienzos del siglo XVII.

En dichos alojamientos, que parecen haber sido levantados con la ayuda de los "indios amigos" (16) se advierte la presencia de militares que vivian con sus familias. Por lo general, era el caso de las autoridades de los tercios (17) y también el de algunos soldados que en calidad de casados o amancebados, habitaban con su mujer e hijos en los dos tercios o fuertes (18). Claro está que unos y otros eran los menos, porque la gran mayoría de los que servían en dichos lugares eran hombres solos, que ocupaban las galeras en grupos integrados por cantidades variables de soldados. Sin perder de vista que las fuentes consultadas sólo posibilitan una aproximación a las cifras reales (19) se ha calculado que en el tercio de Yumbel vivian entre nueve y diez hombres por galera (20) entre seis y ocho en el de Arauco (21), en el fuerte San Juan entre cinco y seis (22), en el fuerte Tucapel

(14) AGI, Chile 130.

(15) Ibidem.

(16) GONZÁLEZ DE NáJERA [8], pág. 277.

(17) Descripción del Tercio de Arauco en 1690 en AGI, Chile 129.

(18) Referencias al amancebamiento en Diego ROSALES, Historia General de el Reyno de Chile, Valparaíso, Tomo II. Imprenta del Mercurio. 1878, págs. 402 y 403,542 y 561 .

(19) El problema fundamental de nuestras fuentes es que los datos que poseemos sobre el número de galeras corresponde a un informe del año 1709, que no incluye cantidad de soldados. Como no se han encontrado datos sobre los soldados que servían en el ejército dicho año se ha hecho el cálculo sobre la base de la población militar del año 1700 . Somos conscientes que en nueve años la cantidad de soldados puede haber aumentado o disminuido y, por lo mismo, nuestro resultado de tantos hombres por galera debe considerarse solo como una aproximación a la cantidad real.

(20) Sobre las galeras informe elaborado en 1709 sobre el tercio de Yumbel y Arauco, y los fuertes San Juan, Tucapel y Purén, en AGI, Chile 130. Sobre los fuertes restantes dicho informe no indica la cantidad de galeras que había en ellos sobre cantidades de soldados. Pagamento al ejército en 1700 en CUNILL [9] pág. 44.

(21) Ibidem

(22) Ibidem. 
alrededor de siete (23) y que en el fuerte Purén lo hacían entre veintidós y veintinueve soldados por galera (24).

A comienzos del siglo XVII, sabemos que en el fuerte que servía González de Nájera ni siquiera los soldados heridos tenían "cama donde poderse desnudar..." (25). Y que seguramente otro tanto ocurría con los sanos. Con el tiempo, sin embargo parece haberse generalizado el uso de camas. En invierno, de acuerdo con una descripción del gobernador marqués de Baides, era usual que los soldados optaran por construir «barbacoas colgadas de los techos" (26). Así, al no quedar las camas a ras de suelo, se aminoraba la humedad que producían los «muchos caños de agua" (27) que entraban a los ranchos cada vez que las lluvias desbordaban los ríos cercanos a los fuertes y tercios (28) o inundaban el lugar donde éstos se encontraban emplazados. En todo caso, la humedad y el agua virtualmente imposibilitaban «encender lumbre" en las "galeras", motivo por el cual los soldados quedaban muy expuestos - como lo decía el gobernador marqués de Baides- a "enfermar y morir" (29). En esas camas, que se fabricaban con cañas y mimbres, sabemos que los militares se acostaban "perpetuamente vestidos» y sólo cubiertos con la «frezada" que se les entregaba para que usaran durante todo un año (30). Lo que desconocemos es si dormían dos hombres por cama, como en el ejército de Flandes (31) o si existía una para cada soldado en las galeras de la Frontera.

En el interior de las galeras solía haber una mesa de madera y algunas sillas en las que los soldados, después de concluir sus obligaciones diarias, se sentaban para comer, disfrutar las emo-

(23) Ibidem.

(24) Ibidem.

(25) GonZález de NáJera, [8], pág. 186.

(26) El gobernador marqués de Baides al rey Concepción, 19 de mayo de 1640, en AGI Chile 21. Su descripción corresponde al fuerte San Francisco de Angol.

(27) Ibidem.

(28) Por varias razones los emplazamientos defensivos se construían cerca de los ríos. En primer lugar porque las aguas de éstos se utilizaban para beber, preparar comida y lavar la ropa de los soldados, y en segundo término, porque varios fuertes se instalaron próximos a los rios con el objeto de proteger los vados que utilizaban los indios en sus incursiones.

(29) El gobernador marqués de Baides al Rey, Concepción, 19 de mayo de 1640 en AGI Chile, 21.

(30) "Relación de la que monta el vestido y comida de un soldado", 1608, en AGI, Chile. 18. También inclica que los soldados duermen vestidos Francisco Núñez de: Pinf:da y Bascuñán, Caltliverio Feliz Santiago, en Colección de Historiadores de Chile. Tomo III. Imprenta del Ferrocarril 1863, pág. 366.

(31) Parkik, [1], pág. 210. 
ciones del juego o simplemente, para "platicar" y "comunicarse cosas" (32). En ocasiones, asimismo, se divertirían escuchando a un compañero que como el sargento Martín de Ibarra, "sabía cantar y tocar cítara y biguela, danzar, escrebir y contar, esgrimir y componer versos» (33). De cualquier forma, la mesa y las sillas constituian un ámbito de sociabilidad, que resultaba útil para procurar, por medio de juegos de azar y otros entretenimientos, o puramente charlando, distraerse en medio de la monotonía del mundo militar de la Frontera.

\section{El VESTIDO}

En Chile, según un informe del año 1608, la vestimenta del soldado de infantería - el más numeroso del ejército- estaba compuesta por un sombrero de color pardo o negro, un "calzón", "un capotillo", un jubón, dos camisas, dos pares de medias de "lana de colores", nueve pares de zapatos y una docena de cintas de gamuza que usaban como adornos (34). A primera vista, da la impresión que este uniforme no era muy diferente al que recibían los soldados en Flandes. A éstos, en efecto, se les entregaba un gabán, calzones, chaqueta, camisa, ropa interior y medias, además de un par de zapatos y un sombrero que solían decorar con plumas (35). Estos adornos, así como el uso de colores vistosos, servían para satisfacer la vanidad de los hombres que combatían en Flandes (36). En Chile, por la misma razón, los soldados gustaban ataviar sus uniformes con cintas de gamuzas y atendían su imagen - lo que no siempre fue bien visto por las autoridadesdejándose el pelo largo, cuidando extremadamente su "coleta» y rapándose la «barba y el bigote por parecer más mozos y no descubrir las canas» (37).

En un comienzo, parte importante de los artículos que componía el equipo del soldado en Chile venía desde Perú. Así el gobernador Alonso de Ribera trajo desde ese país sombreros, jabones, camisas, medias y zapatos, además de algunos géneros

(32) PIneda, [30], pág. 27, usa estas expresiones al describir su conversación en el tercio de San Felipe, con el gobernador Luis Fernández de Córdoba.

(33) Rosal.es [18], II, pág. 502.

(34) "Relación de lo que monta el vestido y comida de un soldado infante en un año" en AGI Chile 18.

(35) PARKFR, |1], pág. 207 y 208.

(36) Ide'm, pág. 208.

(37) Pintida |30|, págs. 299 y 300. 
que se emplearían para elaborar en Concepción las prendas que fuera menester reponer (38). A poco andar, sin embargo, la tendencia fue que elaborara en Chile la mayor parte de los artículos que integraba el equipo del soldado. El mismo gobernador Ribera, por lo demás, teniendo en cuenta que de Lima no «le traían para los soldados zapatos, sombreros..., sacó algunos (soldados) que sabían destos oficios y puso sombrerería (y) zapatería” (39). No parece que este esfuerzo artesanal hubiera tenido mayor éxito toda vez que, en la década de 1630, el gobernador Laso de la Vega dispuso nuevamente que esos artículos se fabricasen en el país. Respecto a otras prendas, sabemos que en 1612 se pagaban "a diferentes personas» de Concepción 4.155 pesos por la fabricación de 831 camisas (40) y que en 1619 Martín Avila, sastre de esta ciudad, recía «novecientos y tantos patacones ... para hacer vestidos a los dichos soldados" (41). Hecha la ropa, que debe haber significado una no despreciable actividad artesanal para Concepción, se les repartía "por el mes de septiembre, por ser los tiempos muy rigurosos de lluvias, y no poderse conducir la ropa a los tercios por esta causa más temprano y así se guarda en los Almacenes Reales para conducirla a este tiempo" (42).

En 1632, como se dijo, el gobernador Francisco Laso de la Vega ordenaba que los zapatos que usaban los soldados fueran hechos en Chile. Con tal objeto, "sacó con gran rigor, prendiéndoles para ello, muchos indios oficiales zapateros, que envió cuarenta leguas de esta ciudad (Concepción) al Corregir del Maule, que hizo asiento de dar los dichos zapatos, donde los tienen como a esclavos, ausentes de sus mujeres, hijos" (43). En 1648, el asiento de los zapatos lo tenía el maestre de campo Fernando de Mieres, manteniendo el control sobre el mismo hasta por lo menos 1673 (44). Seguramente se fabricaban con cordobanes, como solía acontecer con buena parte del calzado corriente que se elaboraba en el país (45).

También el gobernador Laso de la Vega se preocupó de que

(38) AGI, Patronato, 228, ramo 5.

(39) Rosal.t:s |181. Ill, pág. 394.

(40) "Relación de lo que ganan y paga.... 1612" en AGI, Chile 19.

(41) Inlorme del visitador Juan Bautista de Ureta, en AGI, Chile 19.

(42) AGi, Chile 7.

(43) El oidor Pedro Machado al Re'v 1634, AGI Chile 10.

(44) AGI, Chile 62.

(45) Armando de Ramón y Josi Manuel Larrain, Origeness de la vida éconómica ehilena, Santiago Contro de Estudios Públicos, 1982, pág. 179. 
la fabricación de sombreros se hiciera en Chile, para lo cual - según el oidor Pedro Machado-, hizo llevar a Concepción algunos «indios sederos... para el asentista de los sombreros» (46). El negocio indicado no debe haber tenido mayor éxito, puesto que la documentación indica que Pedro Reyna, aproximadamente en 1636, había hecho asiento en Lima para abastecer de sombreros al ejército de Chile durante tres años, y que en 1648, renovaba ese contrato por tres años más, obligándose a entregar 2.000 sombreros anuales, mil negros forrados, en tafetán negro de Castilla, seiscientos «mezclas aforrados,... y cuatrocientos fraileros y aplomados, forrados en badanilla" (47). En 1680, las cuentas del situado señalan como una de sus partidas los pagos que se hacían a los fabricantes de sombreros de Lima (48).

La verdad es que los soldados no siempre contaban con el equipo indicado, y más bien habría que decir que la imagen que proyectan las fuentes corresponde a la de militares pobremente vestidos. Varias razones explican este hecho. En primer lugar hay que tener en cuenta que los artículos indicados se deterioraban más o menos rápidamente, y que no siempre podían ser reemplazados en el momento que correspondía. Los zapatos, por ejemplo, en el ejército de Flandes duraban un año (49). En el ejército de Chile, en cambio, sólo alrededor de un mes (50). Después, debían ser reemplazados por otro par, que no siempre se les entregaba oportunamente. De paso, digamos que dicho tiempo era la duración normal para el calzado corriente que se fabricaba en Chile (51). Por otro lado, bastaba un atraso en las mercaderías que formaban parte importante del situado (52) para que los artesanos de Concepción no pudiesen fabricar oportunamente las prendas que era menester reponer. En segundo término, hay que apuntar que no pocas veces los soldados, después de recibir su equipo, vendían parte del mismo para conseguir algo de dinero. En este sentido, hay datos que posibilitan afirmar que,

(46) AGI, Chile 10.

(47) AGI Contaduría 1722-B y 1755.

(48) "Los oficiales Rosales de esta Caja pondrán certificación en mis manos de la memoria de mercaderías de Castilla y de la tierra que se compraron en los dos situados últimos" en AGI Chile 129.

(49) PARKER [1], pág. 209.

(50) Informe del oidor Bernardo Laya Bolivar 1690, en AGI Chile, 129.

(51) RAMÓN Y LARRAIN, [45], pág. 180.

(52) Juan Eduardo Vargas CARIOla, "Financiamiento del ejército de Chile durante el siglo XVII" en Estudios (Nuevos y Viejos) sobre la Frontera. Coordinados por Francisco de Solano y Salvador Bernabeu, Anexos de Revista de Indias Madrid 1991, págs. 381-384. 
a fines del siglo XVII, los militares vendian sus zapatos al mismo asentista que los fabricaba (53) y que las autoridades, a fin de poner fin a dicho negocio, dispusieron entregar un par de zapatos al mes al soldado soltero y dos pares al casado (54). Y no todo el calzado -doce y veinticuatro pares, respectivamente- que necesitaban a lo largo del año. En todo caso, la razón principal que explica sus dificultades para equiparse adecuadamente estriba en que, a lo largo del siglo XVII, el militar debió adquirir, con su remuneración, sus armas, vestimenta, equipo y comida, y que las autoridades del ejército, regularmente, les vendieron dichos artículos a precios que estaban por sobre los normales de la plaza. Todo nacía de un hecho muy simple. Como hemos explicado en una investigación anterior (55) el situado que llegaba a Concepción no alcanzaba para cancelar los llamados "gastos particulares" y los préstamos que se hacían al ejército y los sueldos de los soldados. Ante esta situación, las autoridades, después de cancelar los "gastos particulares" y los préstamos, que de hecho tenían preferencia sobre los sueldos, cubrían estos últimos "echando creces a los géneros de la ropa" que se traía de Lima. Hubo años en que este procedimiento no se empleó. Pero en otros el "crecimienton llegó al 4 y 7 por ciento, respectivamente. Y en muchos subió al 16, 20 y 25 por ciento. En la década de 1670, el gobernador Juan Henríquez informaba que siempre había sido menester "echarle a la ropa de crecer un setenta u ochenta por ciento" (56). Los altos precios de la vestimenta, en suma, reducían notablemente la capacidad económica del soldado para adquirir con su sueldo todo lo que le resultaba necesario en el mundo de la Frontera.

Por lo que fuera, los soldados no siempre tenían la vestimenta que necesitaban para servir en la Frontera explicaba González de Nájera, que "la desnudez ... que pasan los soldados no sé en qué largo y apretado sitio de tierra se (puede) padecer mayores, porque en cuanto al vestir es todo lo mísero que se puede decir, pues andan descalzos de pie y pierna" (57). El mismo cronista anotaba que los soldados "vense descalzos como los indios" (58) y el cabildo de Concepción afirmaba que las autoridades del

(53) Informe del oidor Bernardo Laya Bolivar, 1690, en AGI, Chile 129.

(54) Ibidem.

(55) VarGias [52], pág.

(56) Idem, pág. 190.

(57) González de Náslira, [8], pág. 189.

(58) Idem, pág. 192. 
ejército, ante la escasez de ropa, no tuvieron más remedio que obligar a los soldados a vestirse "con mantas de indios" (59). La verdad es que la "desnudez" que padecía el soldado en Chile no era muy diferente a la que soportaban los militares en otros lugares del Imperio. A fines del siglo XVI, por ejemplo, se informaba que en Galicia, Portugal, Cádiz, Melilla, Gibraltar y Orán, Navarra, Fuenterrabía, San Sebastián, en Aragón, Ibiza, Menorca y Cataluña las tropas "sufrían privaciones tan extremas que vestían harapos» (60). En Flandes por otro lado, los soldados, al poco tiempo de recibir sus equipos se convertían "en viejos y harapientos pícaros" o en "lastimosas bandas de adefesios helados de frío" (61). Así, pues, el problema de la vestimenta, al que debe agregarse el de los sueldos y la alimentación, se vivía en todas partes, siendo su origen la incapacidad del gobierno repetida a lo largo del siglo XVI y XVII- para financiar adecuadamente su enorme gasto militar (62).

\section{LA ALIMENTACIÓN}

De acuerdo con las costumbres militares de la época, a los soldados que servían en la frontera se les vendían sus raciones de trigo o harina, carne y sal. Un soldado de infantería, según González de Nájera, recibía al año cuatro fanegas de trigo o cebada (63). Una fuente posterior, en cambio, indica que se le entregaban sus fanegas de trigo, además de una vaca y media y una arroba de sal (64). A un soldado de caballería, en cambio, se le proporcionaban ocho fanegas de trigo o harina (65) y una cantidad de carne y sal que probablemente sería superior a la que se le daba al infante. Por último, sabemos que los capitanes recibían tres vacas (66) y una cantidad de trigo o harina y sal

(59) El cabildo de Concepción al rey Concepción, 26 de abril de 1623, en AGI Chile 28.

(60) I. A. A. Thompson, Guerra y Decadencia, Barcelona, Editorial Critica, 1981, pág. 95.

(61) PARKer [1], pág. 209.

(62) THOMPSON [60], pág. 85 y ss.

(63) GonZÁlez dE NáJERA, [8], pág. 189.

(64) "Relación de lo que monta el vestido y comida de un soldado infante en un año" en AGI, Chile, 18.

(65) Informe de Pedro Urcueta Guevara, teniendo de veedor, al virrey del Perú, 1625, en AGI, Chile, 9.

(66) "Relación de los sueldos que paga su Mag...", 1611, en AGI, Patronato, 229 , remo 43. 
que no hemos podido precisar. En total, sabemos que se requerían entre 14.000 y 18.000 fanegas de cereal al año para satisfacer las necesidades alimentarias de los militares que servían en el ejército (67).

Centrándonos en los soldados, indiquemos que su ración de trigo o harina se les entregaba una vez al mes. El "factor" de cada fuerte y tercio era el encargado de recibir el trigo o la harina, guardarlo en los almacenes y repartir las cantidades correspondientes a los miembros del ejército (68). En el caso de los animales, sabemos que éstos se dejaban en los potreros del tercio o fuerte, y que se iban matando de acuerdo a las raciones que semanalmente era menester repartir.

¿Qué hacía el soldado con el trigo o la harina? González de Nájera cuenta que los militares molían el trigo o cebada "a fuerza de brazo, no sin trabajo... sobre unas piedras encavadas con otras menores al uso de los indios, lo cual molido cuecen en agua simple, pues no solamente no tienen otro mantenimiento, pero ni aún sal que de sabor a tan pobre y tasada ración" (69). El padre Diego de Rosales anota que, hasta comienzos del siglo XVII, "Se les daba a los soldados la ración en grano y sólo comían trigo cocido, y si querían comer pan lo habían de moler a mano con gran trabajo" (70). Jerónimo de Quiroga, por su parte, explica que "llamaban al pan que se hacía pan de sangre y yo comí alguno aunque nunca me tocó la tarea de molerlo y es cierto que lo mal molido de la piedra se acababa de moler con los dientes» (71).

En suma, durante los primeros años del siglo XVII, cuando no había molinos en Concepción ni en los lugares donde servían los soldados, lo habitual era que se les entregase una ración de trigo que comían cocida o tostada y molida si deseaban preparar pan (72). En el ejército de Flandes el pan era el principal alimento del soldado (73) y sus autoridades consideraban que éste necesi-

(67) VARGas [4], pág. 367.

(68) "Cuadernos de las cuentas que ajustó en la ciudad de Concepción el sargento mayor Jorge Lorenzo de Olivar, veedor general del ejército...", 16681673, en AGI, Contaduría 1860. Debo el conocimiento de esa documentación al profesor Juan Guillermo Muñoz Correa.

(69) González de NáJERA, [8], cit. pág. 189.

(70) Rosales [18], II, pág. 394.

(71) Jerónimo Quiroga, Memoria de los sucesos de la guerra de Chile, Santiago. Editorial Andrés Bello 1979, pág. 324.

(72). "Razón de lo que monta el vestido y comida de un soldado infante en un año", en AGI, Chile 18.

(73) PARKir, [1], pág. 205 y 206. 
taba un pan de un libra y media al día para alimentarse adecuadamente ¿Cuánto pan comía el soldado de infantería en Chile? Con la harina que recibía - seis fanegas, como se recordarádisponía de alrededor de $21 / 2$ libras de dicho alimento al día, esto es, aproximadamente 1 kilo 150 gramos (74) lo que representa - al menos en teoria- casi medio kilo más que la ración que debía recibir el militar en Flandes (75).

En 1607, con el objeto de producir harina para el ejército, se disponia la construcción de un molino en terrenos del convento de la Merced en Concepción (76). En él se molía el trigo que comenzaban a producir los estancieros de la Frontera y sobretodo, el que se trata de las haciendas reales de Quillota, Buena Esperanza e isla Santa María (77). Hacia mediados de siglo, cuando las estancias reales habian perdido su importancia, las autoridades del ejército optaron por entregar a un asentista parte importante del abastecimiento de la harina que consumía dicha fuerza. A fines de siglo, el asiento se obtenía por seis años, estableciéndose en el contrato que el proveedor se obligaba a «mantener este ejército ... con la harina y trigo que necesiten ... sean 1.400 a 18.000 fanegas ... las cuales me obligaré a poner y entregar en las plazas por mi cuenta, costo y riesgo". Asimismo, se fijaba el precio al que se le pagaría la fanega y se indicaba que el asentista, como ha "sido costumbre hasta aqui", podrá contar con los indios de los pueblos y reducciones tanto para uel manejo de las escoltas que sirven de esta parte del Biobío, como para la asistencia de los molinos» (78).

Los militares, sin embargo, no siempre recibían las cantidades que les correspondian y —según Pineda y Bascuñán- «las harinas que se (les) traían (eran de tan mala calidad que) ni aún las bestias más hambrientas pudieran llegar a arrostrarla, y por las

(74) Para la conversión de fanegas en libras hemos utilizado el trabajo de Armando de Ramón y José Manuel Larrain, "Una metrópolis colonial para Santiago de Chile de la medida castellana al sistema métrico decimal" en Historia, no 14, Pontificia Universidad Católica, 1979, pág. 32 y ss. y de los mismos autores, Origenes [45], pág. 118.

(75) Decimos en teoría porque al soldado en Flandes se le entregaba al día un pan que pesaba una libra y media, el soldado de la Frontera, en cambio recibía harina con la cual se preparaba el pan, sin que sepamos si con $21 / 2$ libras de harina - que era lo que se proporcionaba- se podía fabricar la misma cantidad de pan, menos o más.

(76) VARGAS [4], pág. 377.

(77) Idem, págs. 374 y 375.

(78) Idem, pág. 406 y ss. 
quejas que los pobres soldados daban... para que como quien lo estaba gobernando de maestro de campo general, pusiese algún remedio en semejante maldad, fue forzoso dar cuenta al gobernador como a superior de todo" (79). En realidad, la mala calidad de los alimentos no era un problema que afectara exclusivamente al ejército de Chile. Antes bien, era una situación bastante común en el mundo militar de entonces. Así, los soldados del ejército español en Flandes se quejaban, en 1631, de la "pestilencia» que tenía el pan que se les había entregado; lo que no debe extrañar si se tiene en cuenta que un año antes, se denunciaba que en el pan se había encontrado ingredientes tales como "desperdicios, harina sin moler, galletas rotas y terrones de yeso" (80). Las consecuencias no se hicieron esperar. Muchos de los que consumieron dicho pan murieron; y "otros muchos que se negaron a comerlo murieron de hambre" (81).

De acuerdo con los datos que hemos reunido, puede sugerirse que el consumo de carne de los hombres del ejército se satisfacía con una cantidad que fluctuaba entre las 150 y 2.500 vacas al año (82). Los grandes centros abastecedores de animales para dicha fuerza fueron Santiago y Tucumán, y Paraguay de manera ocasional. Los animales que venían desde dichos lugares eran conducidos hasta la estancia de Catentoa, y desde aquí, después de un período de engorde llevados a los fuertes y tercios para la alimentación de los soldados (83). Allí se dejaban en los potreros, quedando un "cabo" a cargo del cuidado de los mismos (84). Las matanzas se hacían de acuerdo con las necesidades, y los repartos debían efectuarse todos los sábados (85). Por diversas circunstancias, no siempre se respetaba dicho día, lo que significaba que el soldado, después de consumir su ración semanal, quedara sin carne por algunos días (86). Los soldados comían la carne cocida, sazonándola con sal (87) y partiéndola con los cuchillos que se

(79) Pineda [30], pág. 235.

(80) PARKFi [1], pág. 207 y nota 14.

(81) Idem, pág. 207.

(82) VarGias [4], pág. 379.

(83) Idem, págs. 380 y ss.

(84) El potrero del Tercio de Arauco, en AGI Mapas y Planos, Perú y Chile, 23.

(85) Pinida [30], pág. 376.

(86) Ibidem.

(87) Según González de Nájt:RA, [8], pág. 189 no siempre los soldados contaban con sal "que de sabor a tan pobre y tasada ración...". 
les entregaban como parte de su equipo (88). Es posible que también aprovecharan algunas de las vísceras del animal, y que las mujeres que los acompañaban o vivían con ellos les cocinaran la carne, el trigo y los demás alimentos que conseguían (89).

Harina y carne eran los componentes básicos de la dieta de los soldados. Pero no parece que los únicos. En primer lugar, porque da la impresión que en los fuertes y tercios se solía sembrar a sus alrededores. En 1611, por ejemplo, el gobernador Juan Jaraquemada ordenó que se sembraran en Lebu 120 fanegas de trigo, 30 de cebada, 2 de habas, una de garbanzos y media de lentejas. El trabajo corrió por cuenta de seiscientos «indios amigos... los que en quince días a pala" acabaron sementera (90). Más adelante, en lugares como el Tercio de Arauco, se aprecia que alrededor de cada galera había una huerta, regada con el agua de las vertientes cercanas al lugar (91) y probablemente trabajada por los «indios amigos» que vivían en dicho tercio. Por otro lado, agreguemos que algunos gobernadores vendieron vino (92) y miel (93) a los soldados, y que a veces llegaban "vivanderos" a ofrecer sus productos en los fuertes y los tercios (94).

Volviendo a nuestra pregunta. Parece claro que los soldados, además de sus raciones de harina y carne, tenían posibilidades de consumir los productos que se cultivaban en los fuertes y tercios, y los que solían venderles los "vivanderos" y algunas autoridades del ejército. Con todo, diversos testimonios sugieren que los soldados se veían afectados por falta de alimentos para

(88) "Relación de lo que monta el vestido y comida de un soldado infante en un año..." en AGI, Chile 18.

(89) Rosales [18], pág. II, págs. 102 cuenta que en 1604, "los que sirven en ella (la guerra) con ostentación... (llevaban) dos indias o mestizas por criadas... las cuales, aunque es verdad que para sustentar y hacer de comer y lavar a la gente que consigo llevan de camaradas y criados las reputan por necesarias, y con razones aparentes lo justifican diciendo que si no llevan criadas que hagan de comer, el servicio se pierde...".

(90) TRIBaldos DE TOLEDO, [9]. 113 (vta).

(91) Cunill [9], págs. 49.

(92) Juan Eduardo Vargas CARIOI.A, "Notas sobre el gobierno militar en Indias el caso del ejército de Chile en el siglo XVII" en Revista Chilena de Historia del Derecho, Santiago n 15, pág. 229.

(93) Información de Félix Bustamante de Zeballos sobre los negocios del gobernador Juan Henríquez, en AGI, Chile, 7.

(94) Quiroga [71], págs. 387, indica que durante el gobierno de Antonio de Acuña y Cabrera, Juan de Salazar en Tucapel, "tenía cercados a los soldados sin permitir que entrase ningún vivandero...". 
satisfacer sus necesidades. Así González de Nájera narra que cuando

se acabaron las tasadas raciones de trigo y cebada, ordené al principio que, de dos compañías que conmigo tenía, saliese cada día la una a los infructuosos y estériles campos a traer cardos, de los que en España suelen dar verde a los caballos ... y acabados... (los soldados) cargaban de otras yerbas no conocidas, de que me enfermaban algunos, y los sanos ya no se podían tener en pie. Salía yo cada día... iba río arriba, de cuya ribera traía gran cantidad de pencas de áspera comida, de unas grandes hojas mayores de una yerba llamada pangue... Llegó finalmente el extremo de la hambre a tales términos, que no quedó en el fuerte adarga ni otra cosa de cuero, hasta venir a desatar de noche la palizada de que era hecho el fuerte, para comer las correas de cuero crudío de vaca y podridos de sol y agua, con que estaba atado el maderame ... Solí matar con una escopeta algunos perros campestres ... los cuales llegaban de noche al fuerte, y no faltaban soldados y aun más que soldados, que los asaban y comian (95).

La descripción de este cronista respecto al problema alimentario de los soldados, que corresponde a los primeros años del siglo XVII, no es muy diferente a la que hace Pineda y Bascuñán veinte años después. Este último afirma, en efecto, que «el soldado (está) toda la vida muerto de hambre» (96) y lo mismo pareciera acontecer hasta fines del siglo XVII. Varias causas pueden explicar esta situación: En primer lugar, era un hecho que el soldado recibía raciones con menos cantidades que las fijadas, y que la producción de las huertas de sus «barracas», que podría haber suplido la falta de alimentos, se veía afectada por el pillaje fronterizo de los indios. Estos también solian «desbaratar... las escoltas» que conducian las provisiones a los fuertes y tercios, con lo cual estos últimos quedaban desabastecidos de aquéllas hasta que las autoridades les remitiesen una nueva escolta (97). Pero, sin ninguna duda, la razón principal obedecía a que las autoridades, según se apuntó, vendían el trigo y la carne a precios superiores

(95) Gonżál.:z de NáJera, [8], cit., págs. 189 y 190.

(96) Pint:Da [30], págs. 377.

(97) Gonzál.F.z dE NÁJl:ra, [8], cit., pág. 188. 
a los normales de la plaza (98). En 1611, por ejemplo, se vendió a los soldados la fanega de dicho cereal a 2 pesos y 6 reales, en circunstancias de que su precio en Concepción fluctuaba entonces entre 1 peso 7 reales y 2 pesos. El mismo año se les cobraron 5 pesos por cada vaca, cuando su precio en dicha ciudad era de 2 pesos y 5 reales (99).

En suma, los altos precios, además de disminuir el poder de compra de los soldados, reducian sus posibilidades de adquirir las raciones que necesitaban para alimentarse adecuadamente en la Frontera. Sin parte de aquéllas, y sin tener seguridad de que las huertas de los fuertes y tercios les proporcionaran la alimentación que requerían, no era raro que careciesen de la comida mínima, e incluso - como cuentan los cronistas- debicron soportar con alguna frecuencia el drama del hambre.

\section{El JUEGO}

El juego, como decíamos, era una de las escasas distracciones que tenían los soldados en la Frontera. Más exactamente, habría que decir que se trataba de una verdadera pasión, no muy diferente a la que entonces se aprecia en el resto de la sociedad española por dicha diversión. Según Bennassar, "se jugaba en todas partes, y todo el mundo, o poco menos, arriesgaba dinero, en la medida de sus posibilidades» (100). Esa actitud -según dicho hispanista - sería el reflejo de que «la riqueza rápidamente conseguida por vías que no son las del trabajo: por las armas, por el favor del poder, por el azar del juego, por lo que sea, es una riqueza llamada a ser dispendiada, más bien que a generar otra... cualquiera fuese su origen o su situación social, gran número de españoles coincidian en preferir el disfrute inmediato de la riqueza adquirida a la previsión que suponen el ahorro y la inversión» (101).

En Chile, desde el siglo XVI, el juego se extendió extraordinariamente (102). Refiere Pereira Salas que Pedro de Valdivia «jugaba muy largo", que el gobernador Alonso de Ribera fue acusa-

(98) VARGAS [52], págs. 387-390.

(99) Idem, pág. 191.

(100) Bartolomé Bennassar, Los españoles, Barcelona, Argos/Vergara, 1976, págs. 155.

(101) Idem, pág. 138.

(102) Eugenio Pereira Salas, Juegos y alegrias coloniales en Chile. Santiago, Zig-Zag. 1946, págs. 189 y ss. 
do "porque autorizaba con sus propios hechos los juegos que el Rey tenía severamente prohibidos" y que esta pasión, de la que participaban desde gobernadores hasta indios, llegó al extremo de que Juan de Mendoza y Saavedra, corregidor del Maule, fue acusado que upor unos y otros motivos había retenido (a las milicias reunidas en un alarde), ocho días, al otro lado del río Maule, impidiendo a los que vivían al sur del río pasarlo, pues él disponía de la barca para cruzarlo. Durante todos estos días, con todo interés, permitió el juego a los milicianos, les sacó dados, naipes y les jugó taba» (103).

El juego era un pasatiempo autorizado en el mundo militar español. Así, Felipe III, en virtud de una real cédula fechada en Madrid el 2 de marzo de 1613, permitía que "los Gobernadores y Capitanes Generales, donde hubiere milicia, dejen a los Sargentos mayores gozar de los aprovechamientos que hubiere de las tablas de juego en los cuerpos de guardia» (104). Los soldados, por lo mismo, no consideraban que jugar fuese algo contrario a las ordenanzas. De ahí que el capitán de infantería Iñigo de Ayala, después de ser acusado por el visitador Juan Bautista de Ureta de haber "tenido y consentido tablas de juego", alegara "que las leyes y órdenes no prohiben los dichos juegos en los presidios, antes es permitido en los de Flandes e Italia" (105).

Da la impresión que Concepción - la capital de la Fronterase convirtió en la capital del juego en Chile. En 1653, de acuerdo con los datos que proporciona Pereira Salas, su consumo de naipes llegó a 2.500 barajas, le seguía Santiago con 1.095, Cuyo con 400, La Serena con 300, Valparaíso con 200 y el partido de Aconcagua con 150 (106). En Concepción así como en los fuertes $\mathrm{y}$ en los tercios, los soldados jugaban virtualmente todo lo que tenían a los naipes (107) y a los dados (108). Por lo general, las apuestas no las hacían en dinero. Y la razón era muy simple: los militares prácticamente carecían del mismo, puesto que buena parte de sus sueldos lo recibían en ropa y comida. Sin dinero, lo normal era que apostasen su vestimenta, alimentos y armas. El

(103) Idem, págs. 191-194.

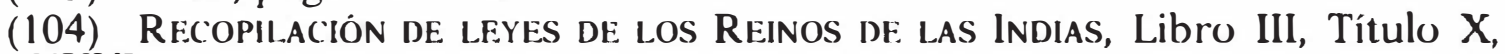
Ley XXVI.

(105) Informe del visitador Juan Bautista de Ureta, 1620 en AGl Chile, 19.

(106) Pereira |102], pág. 198 y 199.

(107) Residencia de Francisco de la Fuente Villalobos, por sus cargos de veedor y proveedor del ejército, en AGI, Escribanía de Cámara, 936.

(108) Informe de Jacobe Adaro San Martín, fiscal de la real audiencia de Santiago al Rey, 1623, en AGl, Chile, 8. 
visitador Juan Bautista de Ureta denunciaba, en 1620, que el maestre de campo Ginés de Lillo tenía "tablas de juego... consintiendo que se jugase (por parte de los soldados) ropa, carneros, vino, caballos y zapatos" (109). El padre Rosales, por su parte, apunta que el gobernador Francisco Laso de la Vega se "condolió de ver (a los soldados) como solían andar descalzos de pie y pierna, rotos, y mal vestidos; tan descaecidos en el traje que no parecían españoles, cuyo defecto se atribuía a las tablas de juego, donde perdian la ropa que se les daba para vestirse, y a otros desaguaderos y empeños que tenían con ellos sus propios oficiales» (110). El mismo cronista añade que dicha autoridad procuraba

obviar los daños del juego, que parece predomina más en este ejército que en otra parte del mundo, siendo allí más nocivo por las circunstancias que le hacen dañoso y perjudicial; $y$ aunque fue rigor el hacer estropear a un soldado que había jugado los afforros (sic) de los calzones con que les habían socorrido, fue de importancia para poner freno a la demasía de los demás en malbaratar los socorros sin atención al lucimiento de sus personas por dar gusto a las manos y cebo al apetito del juego (111).

A fines del siglo XVII, el gobernador Tomás Marín de Poveda informa que los soldados vendían su ropa "para jugar, o la juegan en especie, y faltándoles todo no está segura la espada ni las armas, achaque de que generalmente enferman todos los ejércitos del mundo" (112).

Las autoridades del ejército intentaron evitar que los soldados, antes de partir a la campaña anual, apostaran su equipo en algún juego de azar. En la época, se estimaba que el éxito de la misma dependía en parte de lo bien aperados que estuvieran aquéllos porque «así para la estimación del soldado como para el respeto del enemigo, es de grande importancia que ande bien vestido; que el soldado lucido honradamente se engríe, y bien tratado obra con honra, y al desnudo le desprecia el enemigo y se le atreve como a dominguejo y como a espantajo de huerta,

(109) Informe del visitador Juan Bautista de Ureta 1620, en AGi, Chile, 19.

(110) Rosal.lis |18], Ill, pág. 89.

(111) Idem, pág. III, págs. 89 y 90.

(112) Carta de Tomás Marín de Povedal al Rev, 1689, en ACil, Chile, 129 
que al principio le temen las aves y luego se sientan sobre él (113). Es posible que las autoridades consiguieran sus propósitos y que los soldados, aperados como correspondía, salieran de sus fuertes y tercios a enfrentar a los indios. Aún así, la pasión por el juego era tan fuerte que durante la campaña - al anochecer, en las horas de descanso- los soldados siempre encontrarian compañeros dispuestos a vivir la emoción que significaba apostar, tirar los dados o aguardar las mejores cartas, por cierto que con la secreta esperanza de ganar. La misma que tuvieron dos soldados condenados a muerte por el delito de deserción, a los que el gobernador Pedro Osorez de Ulloa les ordenó que

jugaran al dado su vida, (salvándose de morir quien) en tres veces echase ... más puntos: y habiendo empezado primero... Alejo de Vizcarra echó en tres veces 21 puntos y Miguel García en otros tres 23, y habiendo alegado segunda vez el dicho Alejo de Vizcarra ... se le permitió echase otras tres veces y en ellas echó 22 puntos; de suerte que la suerte le cupo al dicho ... Miguel García (114).

\section{LA CAMARADERÍA}

En el mundo militar de la época parece ser bastante frecuente que surjan entre sus miembros fuertes lazos afectivos (115). Según Geofrey Parker, los que adquirian calidad de amigos pasaban a denominarse "camaradas" y normalmente "vivian juntos (en la misma cámara), compartiendo beneficios y pertenencias, peligros e infortunios" (116). El historiador citado añade que para los «muchos soldados (que) no tenían esposa ni servidores... las estrechas amistades ... que hacían entre los hombres de cada compañía eran importantes" (117). No hay duda que en el ejército de la Frontera también se dio la amistad o camaradería entre sus hombres. El cronista González de Nájera narra que un solda-

(113) RosAl.lis $|18|$, III pág. 90.

(114) Informe de Jacobe Adaro San Martin al Rev 1623, en Acil, Chile, 8. Tambien en informe del visitador Juan Bautista de Ureda, 1620, en AGI, Chile, 19.

(115) Corvislt:R, L'all |2|, 'Tomo II, págs. 873 v 874.

(116) PARKi:k|1], pág. 222.

(117) Ibide'm. 
do, llamado Palacios, "me vino un dia a pedir licencia en el mismo fuerte, para ir a las espaldas del a cortar un haz de carrizo para aderezar su barraca, el cual venía con su arcabuz al hombro y cuerda encendida y diciéndole que no fuese solo, aunque era tan cerca, me dijo que sus camaradas iban con él de la misma manera apercibidos" (118). El gobernador Juan Henriquez, por su parte, afirmaba que la «hermandad de los soldados (era) tal, que unos y otros se acomodan en la distribución del socorro, como en el trabajo y subsistencia" (119).

En medida importante, la camaradería surgía del hecho de que la mayoría de los militares que servía en la Frontera eran hombres solos. Solamente las autoridades de los tercios -en caso de ser casadas - solían vivir con sus familias. Los soldados, incluso los casados, por lo general lo hacían sin sus esposas. Así sabemos que en 1607 el gobernador Alonso García Ramón justificaba haber licenciado a un grupo de militares porque «eran casados en el Perú, y haber pasado diez y doce años sin haber visto a sus mujeres (e) hijos" (120). Es cierto que el amancebamiento de los soldados con indias y mestizas fue un hecho frecuente, y contra el cual poco o nada pudieron hacer las autoridades. Pero dichas relaciones, en la medida que por lo general no eran duraderas, carecían de la fuerza suficiente para romper la soledad familiar en la que se debatía la vida del soldado. Sin esposa e hijos, los amigos resultaban de gran valor, puesto que con ellos podía compartir los peligros, las alegrías, las penas, las esperanzas, las emociones $y$, en fin, todas las vicisitudes del mundo militar.

En cierto modo, esta dimensión humana que tenía la vida militar parece constituir un estímulo para que algunos soldados optaran por quedarse en los fuertes y tercios. Es indiscutible que la deserción era una realidad permanente (121). Pero también lo es que un cierto número de soldados permanecía, y que esta decisión obedecía a que en dichos lugares había hallado la choza, la comida y los afectos que fuera de ellos - sobretodo si era mayor o estaba enfermo- difícilmente iba a encontrar. La ima-

(118) GonZÁlez dE NáJERA, [8], cit., pág. 191.

(119) Juan Henríquez al virrey del Perú, 1670, en AGI, Chile, 56.

(120) "Relación de las cosas que del Reino de Chile se debe dar entero aviso a V.A. por vuestro gobernador Alonso García Ramón", julio de 1607, en AGI, Chile, 18.

(121) Juan Eduardo Vargas Cariola, "Antecedentes sobre las levas en Indias para el ejército de Chile en el siglo XVII (1600-1662)", en Historia, no 22, págs. 336 y ss. 
gen de estos hombres que se quedaban para siempre está dada, en primer lugar, por los documentos que indican el largo tiempo que servían algunos soldados. Así, sabemos que Fernando Trejo, que en 1622 tenía cuarenta y dos años, estaba en el ejército desde hacía veinte y que José María de la Rosa, que en 1703 tenía treinta y tres, servía en esa fuerza desde los diecisiete años de edad (122). Dicha realidad se refuerza al observar que en el ejército -al que por lo general se ingresaba con una edad comprendida entre los dieciocho y veintidós años (123) siempre hubo hombres mayores. En 1654, el capitán Pedro de Sotomayor declaraba tener sesenta y cuatro años, y setenta años reconocía tener el también capitán Antonio Gómez Bejarano (124). Por la misma época, el cronista Jerónimo de Quiroga cuenta que en el fuerte de San Pedro "había veinte viejos que ninguno tenía menos de 80 años...", y que en el fuerte de Colcura también había una compañía de "muchos viejos» (125). En el tercio de Yumbel, a comienzos del siglo XVIII, un soldado llamado Ignacio Capón, decía tener cincuenta y tres años, el capitán Andrés González de Meneses declaraba cincuenta y uno, cincuenta y cuatro el capitán Laureano Ordóñez, cincuenta y ocho el capitán Francisco Niño Ladrón de Guevara, y sesenta y ocho el capitán Diego de Mendoza (126).

¿Que proporción de soldados puede considerarse como viejos? El punto es difícil de responder, porque no hemos encontrado documentación en la cual se indique la edad de los soldados que servían en la Frontera. Así y todo, tenemos algunos informes que proporcionan datos generales sobre el particular. En 1621, por ejemplo, las autoridades señalaban que había 400 soldados entre "viejos y estropeados»; más de un $30 \%$ del total que entonces servía en dicha fuerza (127). En 1679, se afirmaba que 1.000 de los 1.300 hombres con que contaba el ejército eran «viejos y estropeados" (128) y a fines del siglo XVII el veedor Juan Pérez de Piñero sostenía que habían. "muchos soldados viejos (que) no se pueden despedir ... porque no hay forma de reemplazarlos» (129).

(122) AGI, Chile, 134.

(123) VARGAS [4], pág. 124.

(124) AGI, Chile, 53.

(125) QuiroGa [71], pág. 409.

(126) AGI, Chile, 134.

(127) AGI, Chile, 43.

(128) Francisco Hernández de Cifuentes al Rey, 1679, en AGI, Chile, 7.

(129) AGI, Chile, 129. 
Tenemos la impresión de que las amistades entre los soldados se hacían dentro de ciertos límites y posibilidades. En efecto, cuesta imaginar que pudieran ser camaradas un soldado blanco, levado en España, Portugal o en Indias, y uno de los tantos mestizos llegados desde Lima (130). Dejando de lado todas las excepciones que se quieran, hay que partir de la base que el grupo de blancos que servía en el ejército —en el que había soldados y oficiales - siempre consideró una deshonra hacerlo junto a los mestizos que, con el correr del siglo, se constituyeron, en un grupo cuantitativamente importante dentro del ejército (131) Así, el capitán Pedro Moyano, del tercio de Yumbel, declaraba que se había dirigido a la casa del sargento mayor a fin de pedirle, junto a otros compañeros, "les diese satisfacción de haberlos tratado de indios, mestizos y mulatos... a pedirle satisfacción de la honra" (132).

Hay que contemplar, además, que para no pocos miembros del ejército también era una deshonra servir junto a los "desterrados", esto es, el grupo de hombres a los cuales los tribunales de Lima les conmutaban sus penas corporales por servir un determinado número de años en el ejército (133). En 1609, Blas Gago de Figueroa, oficial mayor de la veeduría, indicaba que «los que vienen desterrados a servir entre la gente de guerra... los aborrecen, como en verdad son aborrecidos en la milicia los desterrados por la justicia, mayormente afrentados"... (134). Dos años después, el gobernador Juan Jaraquemada, después de formular un planteamiento similar, solicitaba a Felipe III que no se enviaran más "por la sala del crimen de Lima, ni otra justicia, mulatos ni personas que estén presos por delitos ..., que estraga esto grandemente el buen nombre de la guerra y los soldados particulares lo sienten por agravio" (135).

$\mathrm{Si}$ bien es cierto que los antagonismos sociales y raciales dificultaban o impedían la amistad entre los soldados, también lo es reconocer que los miembros del ejército, ante un peligro que los afectara, solían dejar de lado dichas diferencias y actuar con

(130) VARGAS [121], págs. 351 y 352.

(131) Ibidem.

(132) Antecedentes sobre el motín de 1702-1703, en AGI, Chile, 134.

(133) VARGAS [121], págs. 353-355.

(134) "Relación de los oficiales y soldados que han entrado a servir en este Reino de Chile". Concepción, 15 de noviembre de 1609, en AGI, Chile, 18.

(135) El gobernador Juan Jaraquemada al Rey 1611 en Claudio Gay, Historia Física y Politica de Chile, París, Imprenta de Mauide y Renou, 1846, tomo II, pág. 248. 
una suerte de espíritu de cuerpo. Esta cohesión entre los miembros del ejército - un rasgo muy difícil de detectar - se manifestó con claridad durante el motín de 1702 y 1703. A los responsables se les debían aplicar las duras penas que imponían las ordenanzas militares en estos casos. Las autoridades, sin embargo, prefirieron no hacerlo, "porque considerando que esta conjuración había sido universal en todas las guarniciones de la Frontera, si se pensaba a ser demostración con la de Yumbel era constante el que moviesen los demás" (136). De la misma opinión fue el gobernador Francisco Ibáñez de Peralta, toda vez que -decía«habían tenido noticia ... de la general conspiración que tenían todos los militares para que en caso de que se castigase alguno por el motín que habían hecho, se moverían otra vez todos y perderían sus vidas en la defensa" (137).

Que los amotinados del tercio de Yumbel recibieran la adhesión de otros militares, permite sugerir la existencia de un cierto espíritu de cuerpo entre los miembros del ejército de la Frontera. De ser así, significaría que sus diferencias raciales y sociales, que dificultaban la camaradería, no les impedían unirse para hacer frente a situaciones graves. La verdad que estas reacciones de los soldados se daban en todos los ejércitos, y en general se originaban por problemas relacionados con castigos de la autoridad (como el caso del tercio de Yumbel) o por atrasos en las pagas que recibían los militares. En otras palabras, y empleando el concepto de Corvisier, eran "comportamientos colectivos" (138) que adoptaban los soldados a fin de enfrentar las amenazas de sus superiores $o$, simplemente, para exigir lo que les correspondía.

\section{LA RELIGIOSIDAD}

El cuidado espiritual de los soldados en el ejército de Flandes quedaba bajo la responsabilidad de los capellanes castrenses. En 1572 el duque de Alba, sin hacer demasiadas excepciones calificaba a estos últimos como "ydiotas y viciosos» (139). Parker narra el caso de un capellán que, entre otras cosas, se dedicaba

(136) Junta de Guerra celebrada en Concepción el 19 de enero de 1703, para tratar sobre el motin del tercio de Ymbel, en AGI, Chile, 134.

(137) Ibidem.

(138) CORVISIER, [2], págs. 191 y ss.

(139) Citado por PARKER [1], cit. pág. 216. 
al tráfico de reliquias, tenía un hijo e inclinaciones heréticas (140), y el de otro que se vestía con pieles, llevaba una cadena de oro y «entretenía al obispo de Amberes con baladas impúdicas acompañándose de laúd» ... (141). Aún cuando reconoce que eran casos excepcionales, sostiene que la mayoría de los capellanes castrenses no eran "mucho mejores" que los anteriores y que no pocos «redondeaban sus sueldos ... forzando a los soldados moribundos a dejarles en herencia su dinero»... (142). El nivel de los capellanes - concluye dicho historiador - sólo mejoró a partir de 1587, cuando los jesuitas establecieron la "missio castrensis» en el ejército de Flandes (143).

La presencia de capellanes en los ejércitos -incluso en el caso de sacerdotes íntegros- no parece haber influido mayormente en la conducta de los soldados. Esta, en efecto, poco o nada tenía que ver con los principios de la religión, y más bien se acercaba a un comportamiento particularmente violento y brutal. Fray Antonio de Salazar, en 1655, refiriéndose al paso de los militares por los campos, decia:

Cosa bien astrosa es, y digna de toda reprehensión, ver acabar de robar por los caminos, blasfemar por los poblados, afrentar a uno, herir a otro, violar donzallas, sustentar amigas, andar siempre cargado de mujeres; y luego, sin más disposición que la dicha ...) (144). La investigación contemporánea, por su parte, ha precisado que los militares españoles en Flandes «cometieron incontables violaciones, asesinatos, latrocinios e incendios... (y que) las guarniciones de los Países Bajos españoles ... constituían inevitablemente focos de desorden, juego y vicio, crimen y crueldad, lujuria y desenfreno (145).

Y que, en general, puede afirmarse que la «moralidad de las tropas» (de los ejércitos de la época) por lo general era más bien baja, y que la «violencia, libertinaje de las costumbres y espíritu de lucro" eran rasgos inherentes al carácter de los soldados (146).

Las tareas espirituales, en el ejército de Chile, también corrian

(140) Parker [1], pág. 216.

(141) Ibidem.

(142) Ibidem.

(143) Ibidem.

(144) Julio Caro Baroja, Las formas complejas de la vida religiosa, Madrid, Akal, 1978, pág. 443.

(145) PARKER [1], cit., pág. 225.

(146) CORvisier [2], cit., pág. 193 y 194. 
por cuenta de capellanes. En 1640, existía un capellán mayor, seis capellanes que servían en los diferentes recintos militares y un capellán que tenía la misión de udoctrinar y administrar los sacramentos a los indios que tiene su Mag. en la estancia de vacas... (Catentoa)" (147). Al capellán mayor, por su parte, le correspondía "asistir a la persona del capitán general» (148), incluso cuando salía a las campañas contra los indios. El padre Juan Laso de la Vega, que vino a Chile como capellán mayor del gobernador Francisco Laso de la Vega, informaba al rey en 1634 que había estado a su lado "en cuantas salidas y campeadas ha hecho a tierras del enemigo y batalla que ha tenido, he puesto riesgo a mi vida... arrojándome a confesar a los heridos" (149). En los meses que no había actividad militar - casi todo el otoño y durante el invierno-, dicho sacerdote se ocupaba en Concepción de visitar los «hospitales y componer las conciencias de los enfermos" y todos los días debía decir misa en el campo de guardia. Entre sus deberes, asimismo, estaba upredicar el Adviento y la Cuaresma" (150). Los capellanes, con excepción del que servía en la estancia Catentoa, atendían las necesidades espirituales de los soldados en los tercios y fuertes que estaban a su cargo.

Varios problemas afectaban la labor de los capellanes. En primer lugar, da la impresión que su cantidad no era suficiente para atender a todos los militares del ejército. Por lo mismo, apunta el gobernador Juan Jaraquemada, "se pasa en muchos de ellos (sobretodo en los fuertes) el año que no se celebran (los sacramentos), tomándose las cosas de Dios ... floja y livianamente" (151). En segundo término los capellanes, al estar sujetos a los mismos problemas económicos que soportaban los soldados -esto es, atrasos frecuentes en sus pagas e imposibilidad de cubrir con las mismas todas sus necesidades-, solían abandonar los lugares donde debían ejercer su ministerio. Bernardino Ruiz de la Canal, por ejemplo, sacerdote en el fuerte de Lebu, se fue a la estancia de Pedro Páez Castillejo, uno de los vecinos poderosos de Concepción, con el objeto de "buscar que comer» (152). Por último, tenemos informaciones que indican que el celo pastoral

(147) Planes efectivos del ejército de Chile en 1640 en AGI, Chile 35.

(148) Quirocia [71], pág. 433.

(149) AGI, Chile 12.

(150) Quiroga, [71], pág. 433.

(151) El gobernador Juan Jaraquemada al Rey, Estero de doña Juana, 28 de enero de 1617 en AGI, Chile, 19.

(152) AGI Chile, 20. 
de algunos capellanes fue más bien escaso. Así, hemos encontrado denuncias de que fray Domingo de Andía, capellán mayor en 1620, no cumplía las obligaciones de su ministerio (153); y que los capellanes mayores de fines del siglo XVII no decían misa ni predicaban, «aunque tenían gran divino cuidado de los que morían sin testar, desbarrancados, ahogados o en manos del enemigo, para cobrarles sus sueldos y decirles él las misas" (154). Curiosamente, la misma crítica que se hacía a los capellanes que sirvieron en el ejército de Flandes hasta por lo menos fines del siglo XVI.

Como en otros ejércitos, la conducta de los soldados en Chile estaba lejos de lo que los sacerdotes, con todos los defectos que se quieran, les predicaban. Así, al observar la vida de los militares se aprecia que los actos de violencia -en las diversas formas que podían presentarse- eran un elemento casi habitual en los fuertes y tercios. El gobernador Martín de Mújica, relata que las explosiones de ira, las reyertas y los duelos formaban parte del clima casi cotidiano de los cuarteles (155). ¿Qué impulsaba a los militares a actuar con violencia? Hay que tener en cuenta, por una parte, lo que significaba para aquéllos permanecer durante largos meses virtualmente encerrados en sus fuertes o tercios, sometidos a no pocas privaciones, viviendo en medio de una gran soledad, y sin tener más distracciones que el juego, el ocio y poco más. Rodeados de estas circunstancias, no era extraño que se convirtieran en seres nerviosos y extremadamente irritables, que por asuntos de poca monta - y casi como un necesario desahogo- estaban siempre dispuestos a sacar sus espadas para iniciar pendencias con sus compañeros (156).

Debe indicarse, por otra parte, que los soldados, movidos por su devoción a los ideales de la moral caballeresca, practicaban una conducta que muy poco tenía que ver con lo que predicaba la religión católica. Esta, en efecto, enseñaba a «soportar las injurias con mansedumbre», y "mandaba perdonar y amar a los enemigos e injuriadores" (157). Dicha moral, en cambio, empujaba a que los hombres, "por un punto de honra..., se mataran... El católico español o francés estaba entonces muy lejos de aceptar el precepto evangélico de que si alguien te hiere en la mejilla

(153) Informe del visitador Juan Bautista de Ureta, 1620, en AGI, Chile, 19.

(154) Quirogia [71], pág. 433.

(155) Martín de Mújica al Rey. Concepción, 2 de marzo de 1647, en AGI, Chile, 21.

(156) Rosalks [18], pág. III, pág. 289.

(157) Caro Baroja [144], pág. 432. 
derecha, of récele también la izquierda ... Hechos muchos menos violentos puras cuestiones de etiqueta y tratamiento, daban lugar a peleas feroces" (158).

De acuerdo con la ética caballeresca, tal como se entendía en el mundo de la Frontera, los soldados no trepidaban en desenvainar su espada y morir en defensa de su honra. El capitán Pedro Moyano, como se recordará, declaraba que con otros militares se había dirigido a la casa del sargento mayor a fin de "pedir les diese satisfacción de haberlos tratados de indios mestizos y mulatos... a pedirle satisfacción de la honra» (159). Por cierto que si el sargento mayor no daba satisfacción, los ofendidos le exigirían alguna reparación o zanjarían el insulto por medio de un duelo. En este clima, mínimas of ensas, cuestiones de poca monta, daban lugar a enfrentamientos entre los soldados. Catalina de Erauso, la monja alférez, que conoció la vida del ejército a comienzos del siglo XVII, cuenta que

estábame quieto en Concepción, y hallándome un día en el campo de guardia, entréme con otro amigo alférez en una casa de juego allí junto. Pusímonos a jugar, fue corriendo el juego, y en una diferencia que se ofreció..., me dijo que mentía como cornudo. Yo saqué la espada y entrésela en el pecho (160).

El padre Rosales, al referirse a las reformas que introdujo en el ejército el gobernador Martín de Mújica, indica que "puso mucho freno, y del todo quitó los desafíos y la demasía en las pendencias entre los soldados, sin que osase ya ninguno a sacar la espada en los cuarteles, porque tuvo para degollar a dos personas principales por el caso, y por ser la primera usó de la benignidad y bastó para que todos en adelante se contuviesen» (161).

La verdad es que el clima descrito continuó. Porque era virtualmente imposible poner atajo a un comportamiento que, más que ser producto de buenas o malas normas, reflejaba la fuerza de una mentalidad que, por encima de cualquier cosa, colocaba los valores de la ética caballeresca. El padre Rosales, al

(158) Ibideml.

(159) Motín de 1702 y 1703, en AGI, Chile, 134.

(160) Catalina de Erauso, Historia de la monja allérez, Lima, Serie Perúlibros, 1988, pág. 28. Debo ésta información al prolesor René Millar Carvacho.

(161) Rosales [18], IIl, pág. 289. 
describir esta última, dice que los soldados «tenían por gala la picardía, por donaire la libertad y por bizarría el hurto", y que consideraban que "el soldado que más caballos, bueyes, mulas y indios hurtaba, era el más vizarro; (y que en cambio), el compuesto y contenido era el mayor mandria, el más despreciado y el más para pocon (162). Por mentalidad o lo que fuera, los soldados practicaban la violencia y no se mostraban dispuestos -ni podian- perdonar of ensas, ni tampoco actuar con mansedumbre, honradez y delicadeza. Hacerlo les hubiera significado -ni más ni menos- que el desprecio y rechazo del grupo.

En un terreno distinto, hay que indicar que los soldados con cierta frecuencia vivían amancebados. Los testimonios al respecto se presentan a lo largo de todo el siglo. El virrey del Perú marqués de Montes Claros, en la provisión y placarte para el ejército del año 1612, «encarga al Gobernador y Capitán General excuse todo el exceso de indias solteras y de mal vivir que andan con el ejército y campos" (163). Los jesuitas Vicente Molodell y Antonio de Aparicio, enviados por el padre Luis de Valdivia al fuerte Monterrey, se ocuparon, entre otras cosas, de «quitar juramentos y amancebamientos entre los soldados" (164). Que poco o nada se avanzó respecto al problema indicado lo demuestra el hecho de que el gobernador José de Garro, a fines de siglo, dictara un bando en virtud del cual mandaba que "los cabos y capitanes del ejército ... no (permitieran) en sus compañías amancebamientos escandalosos, ni que con pretexto de criadas tengan (los soldados) en los alojamientos ningún género de mujeres de mal vivir dentro de sus casas, y si hubiere algunas las echen de las plazas dentro de ocho días ..., que se les da término por si quisieren casarse" (165).

Entre los soldados del ejército, asimismo, se detectan algunos casos de sodomía. En efecto, tenemos noticias de que, hacia 1611, una "enfermedad más pestilente (que la viruela y el sarampión) dio a algunos españoles en Paicaví, que fue del alma, porque se hallaron heridos del sodomítico contagio catorce sol-

(162) Ibidem.

(163) Rosales [18], II, pág. 542.

(164) Idem, II, pág. 561.

(165) Bando fechado en Concepción, 5 de noviembre de 1682, en AGI, Chile, 24. 
dados: quemaron los trece y perdonóse al uno por no ser tan culpado. Cosa lastimosa que puede servir de escarmiento a los que son tocados de tan infame vicion(166). Sabemos también que, en 1617, un grupo de soldados desertó del fuerte de Angol para eludir el castigo que merecían "por estar indiciados del pecado de sodomía" (167). Según el gobernador Juan Jaraquemada, dichos militares habían caído en ese vicio debido a uque se tomaban las cosas de Dios ... floja y livianamente por carecer (estos fuertes) de los santos sacramentos y (de) sacerdotes que se los administran" (168).

¿Qué sentido tenía la religión para los soldados en la Frontera si era algo normal la violencia, la venganza, el amancebamiento, los robos y, en fin, otras conductas muy ajenas a lo que les enseñaban los capellanes? En primer lugar, apuntemos que la religión —no obstante el comportamiento esbozado- está presente en la vida de los soldados. Así es muy probable que usaran para protegerse "efigies religiosas, crucifijos, Agnus Dei y otra reproducciones parecidas", tal y como lo hacían los soldados en Flandes (169). En segundo lugar, sabemos que con alguna frecuencia los hombres del ejército de Chile oían misa y comulgaban (170), y que desde 1609 existía en

el Convento de la Concepción del Seráfico padre San Francisco, una capellanía exenta del Ordinario, para la cual había de dar cada soldado doce reales cada uno de su socorro y se le han de decir a cada uno que muere en la paz o en la guerra nueve misas, la una cantada de cuerpo presente y las ocho rezadas, y después doce solemnes en las fiestas más principales del año, y que los capitanes y soldados se habían de enterrar en la capilla mayor del Convento...; y fue de grande importancia esta capellanía porque los pobres soldados que no tenían donde enterrarse ni quien les dijiese una misa, tienen ese grande bien de que aquellos santos religiosos les digan tantas (171).

(166) RoSAlis: [18], II, pág. 510.

(167) Tribal.dos de Tol.EDO, [9], fol. 122 (vta.)

(168) El gobernador Juan de Jaraquemada al rey, Estero de Santa Juana, 28 de enero de 1617, en AGI, Chile, 19.

(169) PARKer [1], cit., pág. 224.

(170) Quiroga [7], pág. 358.

(171) Rosal.r:s [18], II, pág. 485. 
Crucifijos, conf esiones, misas y capellanías. Algo sugieren. Pero hay más. En ef ecto, la documentación sobre el motín de los años 1702 y 1703 posibilita inferir que los soldados sentían temor ante las ideas de demonio e infierno. Así al tomar declaración el tribunal al teniente Juan Contreras, uno de los implicados en dicho motín, se le decía que usi levantaba falso testimonio se lo llevaría el demonion (172). Podría pensarse que la frase indicada no era más que un formulismo, propio de todo proceso judicial de la época. Pero, teniendo en cuenta el miedo que en la época despertaba en el "público sencillo ... (las) intervenciones diabólicas en la vida humana" (173), cabe pensar que los soldados creían efectivamente que el demonio les podía provocar daños graves. En el caso que comentamos, irreparable, puesto que el teniente Contreras, en caso de mentir, perdería la vida eterna. Teniendo en cuenta que los españoles del siglo XVII vivieron "obsesionados por la salvación» (174) ¿será una exageración sugerir que para dicho militar la salvación era un bien fundamental?

La documentación sobre dicho motín, asimismo, permite apreciar otros aspectos de la religiosidad de los soldados. Así, sabemos que los amotinados del tercio de Yumbel, al iniciar su movimiento en contra de las autoridades, hicieron juramento «en forma, hecha la señal de la cruz... delante de un crucifijo» (175). De esta manera, daban seguridades al jefe que habían escogido de que "en todos tiempos empeñaban su palabra de salvarle de cualquier riesgo" (176). Los soldados del tercio de Arauco, por su parte, «encontrándose delante de la imagen de Nuestra Señora, hicieron todos... protestación y juramento de que el hombre que se apartase (de incorporarse al motín) ... y no siguiese el dictamen del común ... lo abaleasen y matasen» (177). Los soldados, en suma, se obligaban a sublevarse ante Cristo, y se comprometían delante de la Virgen a matar a todo compañero que no participase en el motín. Sugerente sincretismo entre la «moral caballeresca y soldadesca» (178) - para la que la matar y vengarse eran actos legítimos-, y la religión cristiana, representada por el respeto

(172) La documentación sobre el motín de 1703 y 1704 se encuentra en AGI Chile, 134.

(173) CARo [144], pág. 68 y 69.

(174) Bartolomé Bennassar, La España del siglo de oro. Barcelona, Crítica 1983, pág. 159.

(175) AGI, Chile, 134.

(176) Ibidem.

(177) Ibidem.

(178) El concepto lo emplea, Caro Bar()ja [144], pág. 432. 
que manifiestan los soldados hacia Cristo y la Virgen, y por su convencimiento de que faltar a las obligaciones contraidas ante Jesús y su Madre - aunque éstas fueran contrarias a la moral católica- podría merecer alguna sanción divina.

Los datos son escasos y, desde luego, impiden cualquier generalización. Aún así, diriamos que la presencia en la vida de los soldados de la Virgen, Cristo y el diablo, o la fuerza que tal vez tenía para ellos la idea de salvación, así como el hecho de que solieran confesarse y escuchar misa, pueden considerarse expresiones de su personal religiosidad. Es cierto que la misma iba escasamente acompañada de una conducta acorde con las enseñanzas de la Iglesia. Pero, si se tiene en cuenta que la religiosidad de los españoles de entonces, no obstante estar impregnada de una fe viva, no se caracterizaba precisamente por la práctica de una moral rigurosa (179), podría aceptarse que lo que ocurría en la Frontera - disociación entre fe y moral- no era del todo diferente a lo que acontecia en el mundo español de entonces. Los grados, desde luego serían distintos. Pero aquí, al igual que en el resto del Imperio, los hombres parece que vivían sin mayores dramas la aparente contradicción que significaba creer, tener una fe viva y, simultáneamente, practicar una conducta que, por las razones que se quiera, era casi ajena a los principios de la religión católica.

(179) Antonio Domincinez OrTiz, El Antiguto Régimen. Los Reyes Católicos y los Austrias, Historia de España. Alfaguara III. Madrid. Alianza Universitaria 1973, págs. 231. 